Pathologe 2020 - 41:444-456

https://doi.org/10.1007/s00292-020-00807-7

Online publiziert: 4. August 2020

(C) Der/die Autor(en) 2020

Schwerpunktherausgeber

H. Baba, Essen

T. Longerich, Heidelberg

\author{
Hans-Peter Fischer ${ }^{1}$ Diane Goltz ${ }^{2}$ \\ ${ }^{1}$ Institut für Pathologie, Universität Bonn, Bonn, Deutschland \\ ${ }^{2}$ Pathologie Koblenz, Koblenz, Deutschland
}

\title{
Autoimmune Lebererkrankungen
}

\section{Hintergrund}

Die Indikation zur Leberbiopsie bei entzündlichen Lebererkrankungen hat sich in den letzten Jahrzehnten erheblich gewandelt. Serologische Untersuchungen erlauben es, Hepatitiden durch hepatotrope Viren zu diagnostizieren und im Verlauf zu verfolgen. Die bioptische Diagnostik ist in diesem Zusammenhang nur in Ausnahmefällen erforderlich. Ultraschall und Magnetresonanztomografie zeigen den entzündlich bedingten Leberumbau auf. Nichtinvasive Messung der Steifigkeit/Elastizität der Leber erlauben Aussagen zum Ausmaß der Fibrose. Die bildgebenden Verfahren, ggf. ergänzt durch ERCP, erlauben es darüber hinaus, die Beschaffenheit der Gallengänge zu beurteilen. Sie sind damit auch wesentlicher Bestandteil zur Diagnose entzündlicher Cholangiopathien, insbesondere extrahepatischer Manifestationen der primären sklerosierenden Cholangitis (PSC) $[8,25$, 37]. Kennzeichnende serologische Autoantikörper in Verbindung mit cholestatischem Leberenzymmuster begründen die Diagnose der primären biliären Cholangitis (PBC) ohne Notwendigkeit einer bioptischen Verifizierung [18, 37].
Mit Ausnahme der Autoimmunhepatitis (AIH) steht die Leberbiopsie erst an späterer Stelle der hepatologischen Stufendiagnostik oder wird durch genannte Verfahren ersetzt $[17,37]$. Hieraus folgt, dass insbesondere untypische Verläufe einer Hepatitis und entzündliche Lebererkrankungen unklarer Ursache der histologischen Klärung zugeführt werden. Die abnehmende Erfahrung mit „typischen“ histopathologischen Krankheitsbefunden steht dem gegenüber. Um diesem Phänomen entgegenzuwirken, ist folgende Übersicht der leberbioptischen Diagnostik primärer autoimmunentzündlicher Lebererkrankungen einschließlich der Overlapsyndrome und Leberentzündungen mit autoimmunologischem Hintergrund gewidmet. $\mathrm{Zu}$ letzteren zählen hepatitische Unverträglichkeitsreaktionen mit Autoimmunphänomenen und Leberbegleitentzündungen bei extrahepatischen Autoimmunerkrankungen.

\section{Autoimmunhepatitis}

Die Autoimmunhepatitis ist eine chronische immunologisch begründete, nicht selbst heilende Leberentzündung unklarer Ätiologie. Sie beruht auf einer aberrierenden Autoreaktivität bei ge- netisch bedingt hierfür empfänglichen Patienten und spricht in den meisten Fällen auf eine immunsuppressive Therapie an. Die Inzidenz der AIH beträgt in Europa ca. 1-2/100.000 Fälle pro Jahr [37], die Prävalenz ca. 10-30/100.000 $[17,37]$. Die Erkrankung beginnt schleichend oder unter dem Bild einer akuten Hepatitis (•Abb. 1) mit einer Vielzahl möglicher Begleitsymptome. Selten sind sehr rasche, binnen weniger Wochen zur Leberdystrophie führende Verläufe. Unter den Leberenzymen führen die eine hepatozelluläre Schädigung anzeigenden Enzyme GOT bzw. AST und GPT bzw. ALT gegenüber GGT und AP. Entsprechend den begleitenden Autoantikörpern und der Altersverteilung lassen sich 3 Typen der AIH unterscheiden ([43]; - Tab. 1). Ungewöhnliche Autoantikörperbefunde sind möglich, so in etwa $10 \%$ der Fälle antimitochondriale Antikörper ohne weitere klinische Hinweise auf eine PBC ([17, 37]; - Abb. 2) oder bislang verdeckte PBC.

Die 3 essenziellen Bausteine der Diagnose einer AIH sind über einem Grenzwert liegende Spiegel der Immunglobuline vom Typ IgG, Autoantikörper im Serum sowie der histopathologische Befund. Auszuschließen ist eine virale $\mathrm{He}$ patitis.

Tab. 1 Gegenüberstellung der 3 Haupttypen der Autoimmunhepatitis. (Nach Washington und Manns [43])

\begin{tabular}{|c|c|c|c|}
\hline Typ & Autoantikörper & Alter zum Beginn (Jahre) & Kommentar \\
\hline 1 & ANA und/oder SMA & $\begin{array}{l}\text { Bimodal; mit Peaks 10-25 } \\
\text { und } 45-70\end{array}$ & Nahezu $90 \%$, gutes Ansprechen auf Therapie \\
\hline 2 & $\begin{array}{l}\text { LKM-1, LKM-2, LC-1; } \\
\text { ANA und SMA negativ }\end{array}$ & $<15$ & $\begin{array}{l}\text { Etwa } 10 \% \text {, } \\
\text { Schwere Aktivität, nicht selten ungenügendes Ansprechen auf Therapie, } \\
\text { häufig Relapse nach Therapie }\end{array}$ \\
\hline 3 & SLA/LP & Um 40 & Selten, klinisch wie Typ 1 \\
\hline
\end{tabular}




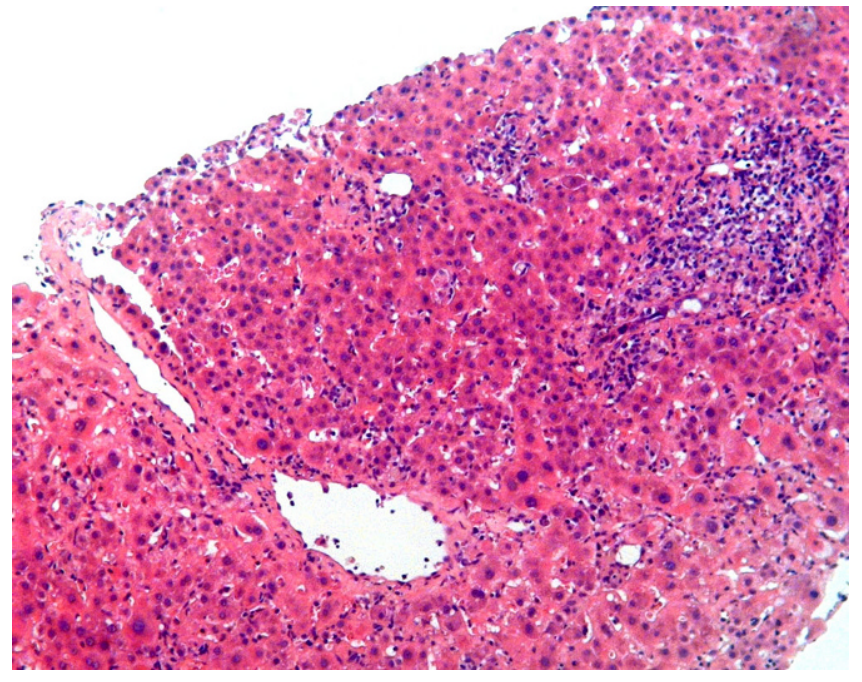

Abb. $1 \Delta$ Akut einsetzende Autoimmunhepatitis mit portaler, periportaler und lobulärer Entzündung, alterativen und regeneratorischen Parenchymzellveränderungen ohne Fibrose (Klinik: Ikterus seit 14 Tagen, ALT: 1484 U/I, GGT 553 U/l; virale Hepatitis ausgeschlossen, lgG im oberen Normbereich, SMA 1: 160 als einziger Autoantikörper). Nach 3 Monaten SMA 1280, ANA 1:320, Ansprechen auf Prednisolon. Nach einem Jahr Leberenzyme im Normbereich

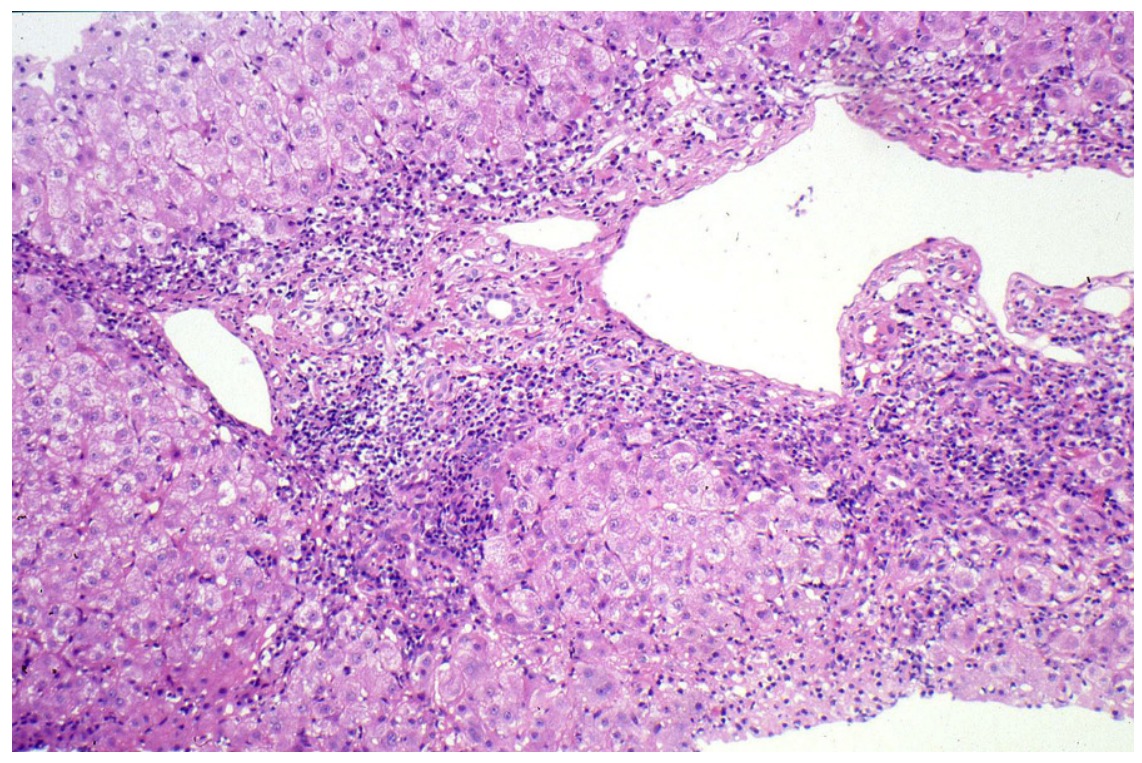

Abb. 2 ム Chronische Autoimmunhepatitis mit periportal dominanter plasmazellreicher "Grenzflächenhepatitis" und periportaler Fibrose. Pathologische Leberwerte seit 1 Jahr. GOT 260, GPT 280, GGT 220, AP 280, Gammaglobuline 22 mg/dl, Nachweis von AMA-M2 und hochtitrig von Antikörpern gegen Doppelstrang-DNA

Histologische Befunde der AIH in Abhängigkeit von der klinischen Präsentation und dem Verlauf:

Der seltene fulminante Verlauf führt binnen weniger Wochen zur subakuten Leberdystrophie.

Die bei etwa $25 \%$ der Patienten primär akut einsetzende Acute-onset-AIH präsentiert sich unter dem histologischen Bild einer akuten panacinären Hepatitis (• Abb. 1). Zentrilobuläre Nekrosen
Bei akutem Schub einer chronischen Hepatitis ist neben der aktiven Entzündung der chronisch entzündliche Vorverlauf der Hepatitis in unterschiedlichem Fibrosestadium zu erkennen. Im Vordergrund steht das Bild der Interfacehepatitis, eine auf den Grenzbereich von Portalfeld und angrenzendem Parenchym konzentrierte Entzündung assoziiert mit lymphoplasmazellulärem Infiltrat, Schwellung, Pyknosen von Hepatozyten (• Abb. 2 und 3). Der Plasmazellreichtum ist typisch aber nicht obligat. Cluster aus mindestens 5 Plasmazellen in Portalfeldern und insbesondere in den Leberläppchen wurden kürzlich als morphologisches Unterscheidungskriterium der AIH gegenüber einer aktiven Hepatitis C herausgearbeitet [20]. Gerade in den periportalen Parenchymbereichen bilden sich Leberzellrosetten aus, bei denen Leberepithelien kreisförmig einen prominenten Gallecanaliculus umlagern (• Abb. 3b). Das Phänomen der Emperipolese, der Inklusion von Entzündungszellen in den Zellleib von Hepatozyten, kann hinzutreten (• Abb. 3b, Inset; [6, 39]). Synzytiale hepatozelluläre Riesenzellen können eine AIH begleiten und zum Bild einer adulten Riesenzellhepatitis führen $[19,39]$.

Etwa ein Drittel der Patienten haben zum Diagnosezeitpunkt eine Zirrhose entwickelt. Hier ist der Verlauf offensichtlich unbemerkt, schleichend [17].

Immunhistochemisch wird das entzündliche Infiltrat portal periportal und lobulär von CD3- und CD8-positiven Lymphozyten dominiert. Unter den Plasmazellen dominiert der Typ IgG [43]. Die histologischen Befunde, insbesondere Interfaceaktivität, Plasmazellreichtum und Leberzellrosetten, gehen mit großem Gewicht in die Scoringsysteme ein (•Tab. 2). Für das Grading und Staging der AIH besteht kein eigenständiges Bewertungssystem. Es werden meist die für virale Hepatitiden vorgesehenen Systeme angewandt [43], die Europäische Practical Guideline [17] und die aktuell gültige S2k Leitlinie Autoimmune Lebererkrankungen [37] schlagen den modifizierten Hepatitis-Aktivitätsindex nach Ishak vor (• Tab. 3 und 4; [22]). Im deutschsprachigen Raum ist der DesmetScore verbreitet [37]. 
Erhebliche Schwierigkeiten bereiten Fälle, die nicht in das kennzeichnende Befundraster der AIH-Scoresysteme passen. Hierzu rechnen:

- panacinäre Hepatitis mit schwerem akutem Verlauf,

- zentrilobuläre Hepatitis mit/ohne wesentlicher portaler Entzündung im Frühstadium des Verlaufs,

- Hepatitis mit negativem Autoantikörperprofil in bis zu $20 \%$ der Patienten (u. a. bei unvollständiger serologischer Abklärung),

- chronische Hepatitis mit untypischem Autoantikörperprofil,

- Overlapsyndrome und

- mutmaßliche Vorschädigung, u.a. durch Medikamente oder andere Erkrankungen, z. B. Morbus Wilson.

Eine entzündliche Einbeziehung kleiner Gallengänge in das dichte portale Infiltrat muss nicht als eigenständige Cholangitis bewertet werden [40]. Granulomatöse oder sklerosierende Cholangitis, schwere Siderose, ausgeprägte Steatose, Kupferablagerungen sind hingegen keine Merkmale der AIH. Sie weisen auf eine andere Ursache der Entzündung oder auf das Bestehen einer Overlapvariante hin.

Der histologische Befund wird sowohl in einem ausführlichen Scoresystem [2] als auch in einem vereinfachten Scoresystem zur Diagnose der AIH ([21]; • Tab. 2) berücksichtigt. Als AIH-typische Befunde werden hierbei die Interfacehepatitis, der Plasmazellreichtum und Leberzellrosetten benannt. Die Zusammensetzung der Scorepunkte verdeutlicht den Beitrag der Leberbiopsie zur Diagnosesicherung [17]. Erfolgt die Leberbiopsie nach eingeleiteter Therapie, ist der Wert der Histologie für die Diagnose einer AIH eingeschränkt [37]. Die Biopsie kann über die Diagnose der AIH hinaus auch zur Überwachung der Therapie, zur Beurteilung der Krankheitsprogression und zur Entscheidung über das Ende einer immunsupprimierenden Therapie genutzt werden.

Die Standardtherapie der AIH erfolgt mit einem Regime aus Prednisolon und Azathioprin, die in $80 \%$ zur Remission führt. Bei Nichtzirrhose kann Budenosid zur Erhaltungstherapie eingesetzt werden. Die Behandlung wird über min-

Pathologe 2020 - 41:444-456 https://doi.org/10.1007/s00292-020-00807-7

(c) Der/die Autor(en) 2020

\section{H.-P. Fischer · D. Goltz}

\section{Autoimmune Lebererkrankungen}

\section{Zusammenfassung}

Autoimmune Lebererkrankungen umfassen ein Spektrum idiopathischer fortschreitender Leberentzündungen mit im Einzelfall histologisch kennzeichnenden Befunden. Hierzu gehören bei der autoimmunen Hepatitis (AlH) das Bild einer chronischen Hepatitis mit plasmazellreicher dominierender Grenzflächenaktivität, Rosettierung der Hepatozyten und Emperipolese, bei der primären biliären Cholangitis ( $\mathrm{PBC}$ ) chronische, nichteitrige, destruierende Gallengangsläsionen, bei der primären sklerosierenden Cholangitis (PSC) die zwiebelschalenartige periduktale Fibrose bis zur verödenden Gangsklerose. Histopathologische Schnittmengenbefunde dieser Entitäten untereinander kennzeichnen Varianten der AlH bzw. Overlapsyndrome. Die Diagnose autoimmuner Lebererkrankungen beruht auf der Gesamtkonstellation klinischer, enzymserologischer, immunserologischer und bildgebender Befunde, zu denen fakultativ oder obligat die Leberbiopsie hinzugezogen wird. Der Leberbiopsie kommt eine gewichtige Rolle zu bei der Diagnose der AlH und ihrer Varianten, der SmallDuct-PSC, der AMA-negativen PBC, der lgG4-assoziierten Entzündungen und der Abgrenzung gegenüber konkurrierenden Lebererkrankungen insbesondere der medikamentös-toxischen Leberschädigung. Damit leistet die histologisch gestützte Diagnose einen gewichtigen Beitrag zu einer differenzierten Therapie autoimmunentzündlicher Lebererkrankungen.

\section{Schlüsselwörter}

Autoimmune Hepatitis · AlH · Primäre Biliäre Cholangitis · PBC · Primäre Sklerosierende Cholangitis · PSC · Overlapsyndrome · lgG4assoziierte Erkrankung · Leberbiopsie Histopathologische Diagnostik

\section{Autoimmune liver diseases}

\section{Abstract}

Autoimmune liver diseases comprise a spectrum of progredient idiopathic inflammatory diseases. Typical histological features of autoimmune hepatitis $(\mathrm{AlH})$ include the pattern of chronic hepatitis with predominant plasma cell-rich interface activity, rosetting of hepatocytes, and emperipolesis. Florid bile duct lesions are the key feature of primary biliary cholangitis (PBC); onion-like periductal fibrosis characterizes the primary sclerosing cholangitis (PSC). Variants of AlH, or overlap syndromes, show intersecting histomorphologic findings with PBC or PSC. The diagnosis of the different autoimmune inflammatory liver diseases is based on clinical presentation, a hepatitic or cholestatic pattern of liver enzymes, immuno-serological findings, image analysis in PSC, and liver biopsy as a facultative or obligatory adjunct. Liver biopsy plays a major role in the diagnosis of AIH, small-duct PSC, AMA-negative PBC, IgG4-related diseases, overlap syndrome, and in the recognition of concurrent liver diseases, especially drug-induced liver diseases. Herewith pathologists can help clinicians find adequate therapy for different autoimmune inflammatory liver diseases.

\section{Keywords}

Autoimmune hepatitis · AlH · Primary biliary cholangitis . PBC . Primary sclerosing cholangitis · PSC · Overlap syndrome · lgG4related diseases - Liver biopsy - Histologic findings destens 3 Jahre und über 2 Jahre nach Normalisierung der Transaminasen und Immunglobuline (biochemische Remission) empfohlen. Die histologische Entzündungsaktivität in Form einer residuellen Interfacehepatitis kann über die biochemische Normalisierung hinaus fortbestehen. Die histologische Remission setzt einen HAI-Wert $\leq 3$ voraus [37]. Die Leberbiopsie trägt zur Bestimmung des Endpunktes einer Behandlung wesentlich bei [17]. Serologisch nachweisbare Autoantikörper, insbesondere ANA, können auch bei biochemischer und histologischer Remission fortbestehen [11, 17, 37]. 
Tab. 2 Vereinfachtes Scoresystem für die Autoimmunhepatitis. (Nach Hennes et al. [21])

\begin{tabular}{|c|c|c|}
\hline Variable & Cut-off & Score \\
\hline ANA oder SMA+ & $\geq 1: 40$ & 1 \\
\hline ANA oder SMA+ & $\geq 1: 80$ & 2 \\
\hline Oder LKM+ & $\geq 1: 40$ & 2 \\
\hline Oder SLA/LP+ & Jede Titerstufe & 2 \\
\hline \multirow[t]{2}{*}{ IgG oder $\gamma$-Globuline } & Über oberem Normalwert & 1 \\
\hline & $1,1 \times$ über oberem Normalwert & 2 \\
\hline \multirow[t]{2}{*}{ Leberhistologie } & Vereinbar mit $\mathrm{AlH}^{\mathrm{a}}$ & 1 \\
\hline & Typisch für AlH & 2 \\
\hline \multirow[t]{2}{*}{ Ausschluss viraler Hepatitis } & Nein & 0 \\
\hline & Ja & 2 \\
\hline Wahrscheinliche AIH & & $>/=6$ Scorepunkte \\
\hline Definitive AlH & & >/=7 Scorepunkte \\
\hline \multicolumn{3}{|c|}{$\begin{array}{l}\text { AIH Autoimmunhepatitis, ANA antinukleäre Autoantikörper, SMA glattmuskuläre Autoantikörper, } \\
\text { LKM Liver-Kidney-Mikrosomen-Autoantikörper, SLA/LP lösliches Leberantigen/Leber-Pankreas An- } \\
\text { tikörper } \\
\text { 'Vereinbar mit AlH: Bild der chromischen Hepatitis ohne die als „typisch“ charakterisierten Kriterien } \\
\text { 'Typisch für AlH: Interfacehepatitis mit lymphozytärer oder lymphoplasmazellulärer Portalfeldinfil- } \\
\text { tration übergreifend auf das Läppchenparenchym. Leberzellrosetten, Emperipolesis }\end{array}$} \\
\hline
\end{tabular}

Tab. 3 Modifizierter Histologischer Aktivitätsindex (mHAI). (Nach Ishak et al. [22])

\begin{tabular}{|l|l|l}
\hline Interfacehepatitis & 0 & Keine \\
\hline 1 & Fokal, wenige Portalfelder \\
\hline 2 & Fokal, Mehrzahl der Portalfelder \\
\hline Konfluente Nekrose & 4 & Kontinuierlich um <50\% der Portalfelder \\
\hline & 1 & Kontinuierlich um >50\% der Portalfelder \\
\hline 2 & Keine \\
\hline 3 & Fokal \\
\hline 4 & Zone-3-Nekrosen, wenige \\
\hline 5 & Zone-3-Nekrosen, zahlreiche \\
\hline 6 & Zone-3- und multiple portozentrale Brücken \\
\hline 0 & Panazinäre/multiazinäre Nekrosen \\
\hline 1 & Keine \\
\hline 2 & Bis 1 Herd pro Gesichtsfeld (10er-Objektiv) \\
\hline 3 & 2-4 Herde pro Gesichtsfeld (10er-Objektiv) \\
\hline 4 & 5-10 Herde pro Gesichtsfeld (10er-Objektiv) \\
\hline 0 Portale Herde pro Gesichtsfeld (10er-Objektiv)
\end{tabular}

\section{AlH in besonderem klinischem Kontext}

Die AIH kann in 10-18\% der Fälle einer APECED (autoimmune Polyendokrinopathie-Candidiasis-ectodermale Dystrophie) bzw. im Rahmen des autoimmunen
Tab. 4 Staging der chronischen Hepatitis.

(Nach Ishak et al. [22])

\begin{tabular}{|l|l|}
\hline $\begin{array}{l}\text { Stadi- } \\
\text { um }\end{array}$ & Histologische Merkmale \\
\hline 0 & $\begin{array}{l}\text { Keine Fibrose } \\
\text { Fibröse Verbreiterung einzelner } \\
\text { Portalfelder } \pm \text { kurze Septen }\end{array}$ \\
\hline 2 & $\begin{array}{l}\text { Fibröse Verbreiterung }>50 \% \text { der } \\
\text { Portalfelder } \pm \text { kurze Septen }\end{array}$ \\
\hline 3 & $\begin{array}{l}\text { Fibröse Verbreiterung }>50 \% \text { der } \\
\text { Portalfelder, einzelne fibröse porto- } \\
\text { portale Brücken }\end{array}$ \\
\hline 4 & $\begin{array}{l}\text { Fibröse Verbreiterung der Portalfel- } \\
\text { der mit ausgedehnter brückenbil- } \\
\text { dender Fibrose (auch portozentral!) }\end{array}$ \\
\hline 5 & $\begin{array}{l}\text { Inkomplette Zirrhose mit einzelnen } \\
\text { Pseudolobuli }\end{array}$ \\
\hline 6 & Komplette Zirrhose \\
\hline
\end{tabular}

auftretende AIH bzw. De-novo-AIH in Lebertransplantaten abzugrenzen [17]. Da sie die Spenderleber betrifft, ist sie nicht strictu sensu autoimmun und kann alternativ als Post-transplant-immuneHepatitis bezeichnet werden. Im pädiatrischen Krankengut ist sie bei nichtimmunologischer Grunderkrankung der Primärleber und in Verbindung mit dem im Abschnitt „Autoimmunhepatitis" angegebenen AIH-Scoring gut definiert und entsprechend einer AIH zu therapieren [23]. Pathogenetisch nicht abschließend bewertet wird die Plasmazellhepatitis der Transplantatleber im Erwachsenenkollektiv, für die auch eine alloimmune T-Zell- und antikörpermediierte plasmazellreiche Rejektion diskutiert wird. Sorgfältiges serologisches AIH-Scoring und Überprüfung auf C4D-Expression sind hier für eine genauere Zuordnung notwendig $[14,23]$.

\section{Primäre biliäre Cholangitis}

Die PBC (früher primäre biliäre Zirrhose) ist eine chronische, immunologisch begründete, nicht selbst heilende, fortschreitende Cholangitis intrahepatischer Gallengänge unklarer Ätiologie. Ihr Endstadium ist eine biliäre Leberzirrhose. $\mathrm{Zu}$ etwa $80-90 \%$ sind Frauen betroffen, meist zwischen dem 30. und 60. Lebensjahr $[18,37]$. Selten sind Patienten jünger als 30 Jahre - der früheste dokumentierte Krankheitsbeginn betraf eine 15 Jahre alte Patientin nach der Menarche [12]. 


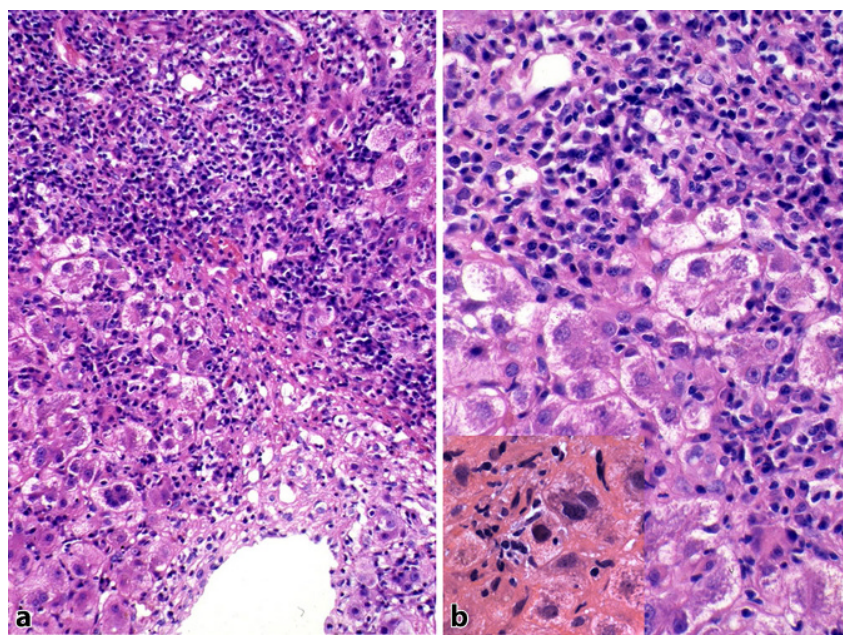

Abb. $3 \Delta$ Chronische Autoimmunhepatitis mit plasmazellreicher Grenzflächenhepatitis und portozentraler Brückennekrose (a). b Leberzellrosetten, Emperipolses im Inset

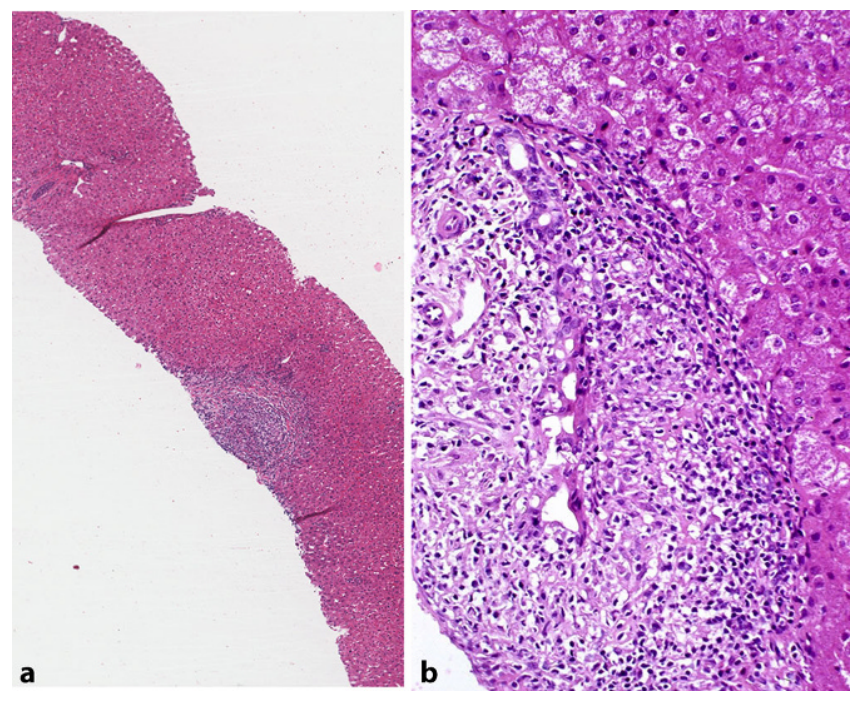

Abb. 4 \ Primäre biliäre Cholangitis (PBC) im Stadium I (Klinik: GPT nahezu normal, GGT 4,5fach über oberer Normwertgrenze, Nachweis von AMA-M2). a Isolierter Befall eines Portalfeldes, b floride Gangläsion mit granulomatöser Komponente

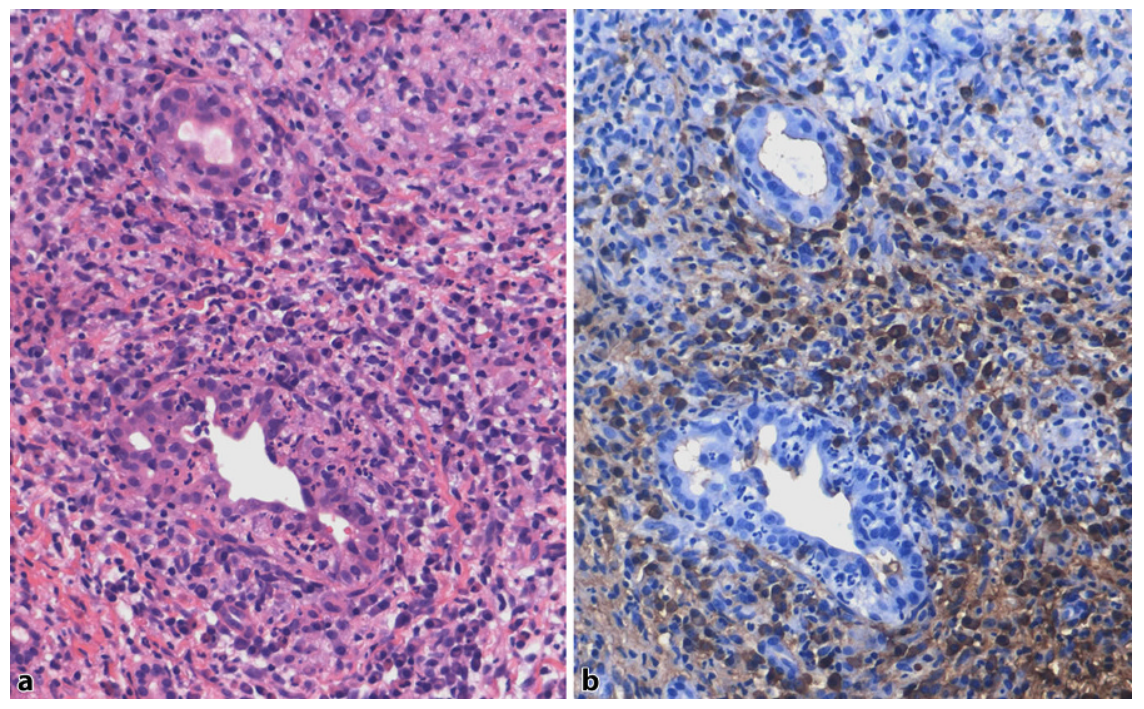

Abb. 5 ム PBC mit florider Gangläsion mit plasmazellreichem, aber auch neutrophil-granulozytärem Infiltrat (a). b Die Plasmazellen dominant vom IgM-Typ

Die PBC ist daher keine Erkrankung des Kindesalters. Die Inzidenz in Europa liegt bei etwa $1 / 100.000$ per anno [18].

Unter den Leberenzymen führen die Cholestase anzeigenden Leberenzyme GGT und AP gegenüber GOT und GPT. Wichtiger serologischer Diagnoseparameter ist der Nachweis antimitochondrialer Antikörper (AMA) vom Typ AMA-M2 [18, 37]. Das historisch benannte "M2-Antigen“ beinhaltet mindestens 5 Untereinheiten, von denen die Determinante M2a bzw. die E2Untereinheit des Pyruvatdehydrogen- asekomplexes (PDC-E2) bei $80 \%$ der AMA-M2 positiven PBC-Patienten als eigentliches Antigen fungiert. In den $10 \%$ der AMA-negativen PBC finden sich in der Hälfte der Fälle PBC-spezifische ANA vom Typ Anti-sp100 mit dem Immunfluoreszenzmuster der "nuclear dots" oder vom Typ Anti-gp210 mit perinukleärem Immunfluoreszenzmuster $[18,30,34,37]$. Einzelne PBC gehen ausschließlich mit Autoantikörpern gegen Zentromere einher [37]. Im Serum können die Immunglobuline vom Typ IgM erhöht sein.
Histologische Befunde der PBC. Die PBC betrifft ausschließlich intrahepatische Gallengänge, hierunter bevorzugt interlobuläre Gangabschnitte von 40-80 $\mu \mathrm{m}$ Durchmesser. Es werden 4 Stadien unterschieden $[35,36,38]$ :

- Stadium 1: Histologischer Schlüsselbefund der portal konzentrierten Entzündung ist eine chronische, nichteitrige, destruierende Cholangitis mit lymphoepithelialen Läsionen, Plasmazellen und gallengangsbezogenen Granulomen (•Abb. 4). Im Gegensatz zur IgG-dominanten Plasmazellinfiltration bei der AIH überwiegen bei einem Teil der PBCFälle IgM-typische Plasmazellen $[1,24]$; neutrophile Granulozyten können mitbeteiligt sein (• Abb. 5). Die Entzündung betrifft punktuell zunächst einzelne Gallengänge bzw. Portalfelder (• Abb. 4). Daher können in frühen Stadien auch bei wegweisenden serologischen Befunden die kennzeichnenden histologischen Veränderungen fehlen oder bei isolierter rundzelliger Infiltration eines einzelnen Portalfeldes erst in erforderlichen Schnittstufen hervortreten.

- Stadium 2: Der Prozess überschreitet die Portalfeldgrenzen mit lymphoplasmazellulärer Infiltration (lymphozytäre Interfaceaktivität) 


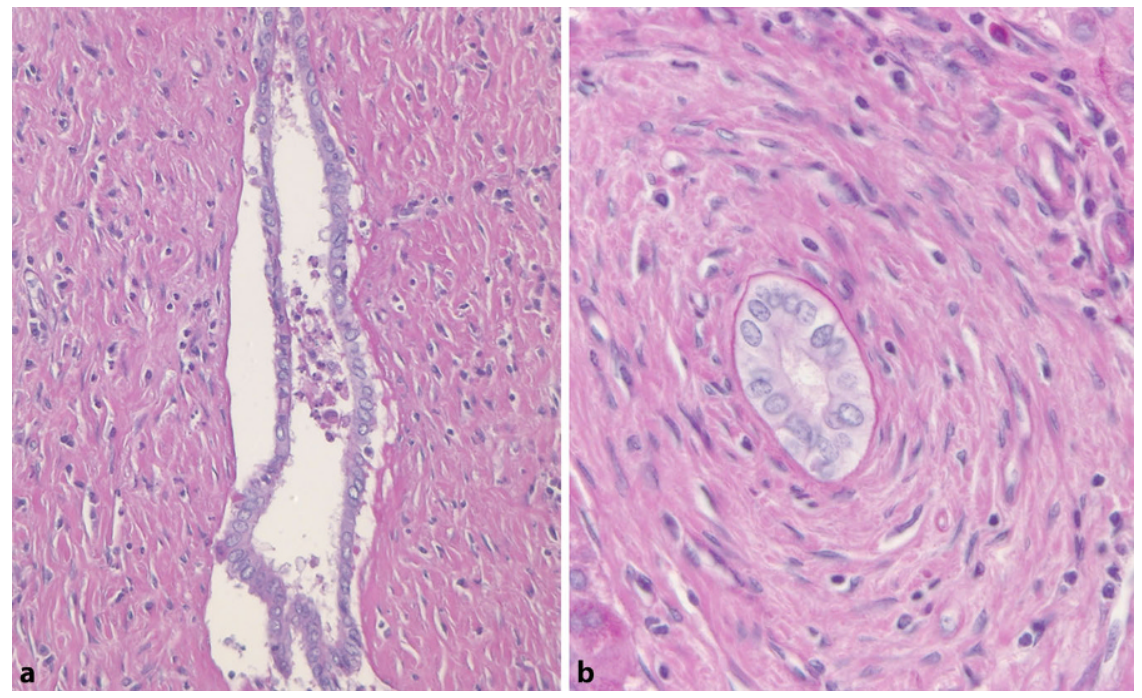

Abb. 6 \ Primäre sklerosierende Cholangitis (PSC) mit Portalfeldsklerose um einen septalen Gallengang mit abgehobener Epitheltapete (a), zwiebelschalenartiger periduktaler Fibrose und distinkt PASpositiver Basalmembran um einer interlobulären Gallengang (b)
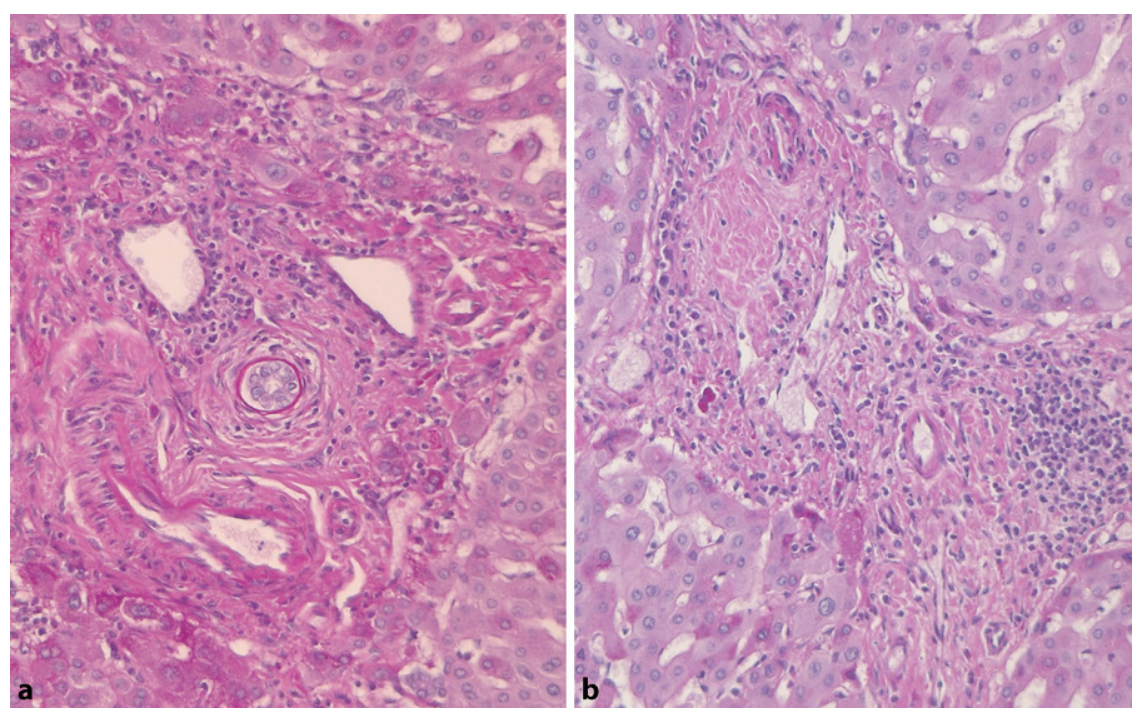

Abb. 7 ^ Primäre sklerosierende Cholangitis (PSC) mit breiter PAS-positiver biliärer Basalmembran (a) und obliterierender Fibrose eines ehemaligen interlobulären Gallengangs neben erhaltener Arteriole und portaler Venole (b)

oder neoduktulären Proliferaten, periduktulären Fibrosen und Cholestase (biliäre Interfaceaktivität). Die Cholestase geht mit fedriger Degeneration der Hepatozyten, Mallory-Denk-Körpern, Ablagerungen von kupferassoziiertem Protein oder histochemisch nachweisbarer Kupferretention einher.

- Stadium 3: Fibrose mit Septenbildung, Gallengangsreduktion, Abnahme der Entzündung.

- Stadium 4: Biliäre Zirrhose, Duktopenie, Cholestase
Auch in fortgeschrittenen Krankheitsstadien können floride entzündlich destruierte Gallengänge neben narbig obliterierten Gangresiduen und neben völlig unaffektierten Gallengängen nachweisbar sein. Dann liegen unterschiedliche Stadien der Erkrankung nebeneinander vor.

In einer neueren japanischen Einteilung [31] werden zur Stadieneinteilung Ausmaß der Fibrose, des Gallengangsverlustes und der Cholestase zusammenfassend bewertet und die entzündliche Aktivität bzw. das Grading hinsichtlich der cholangitischen und der hepatitischen Komponente differenziert. Dieser Score soll eher die Entwicklung einer Zirrhose vorhersagen als die im vorangegangenen Absatz dargestellte Vier-Stadien-Einteilung nach Scheuer [36].

Die Diagnose PBC wird gestellt beim Vorliegen von mindestens 2 der 3 Kriterien (a) chronisch erhöhte Cholestaseparameter über 6 Monate, (b) AMA, insbesondere AMA-M2 oder PBC-spezifische ANA, (c) typische Histologie [16, 18, 37]. Mit dieser Vorgabe kann in vielen Fällen die bioptische Abklärung vermieden werden. Die Kenntnis der Morphologie ist erforderlich, wenn bei klinischerseits unklarer Befundlage die Erkrankung gegenüber anderen Cholangiopathien, z. B. medikamentös-toxisch bedingter cholestatischer Hepatopathie, abgegrenzt werden soll. Indiziert ist die Biopsie bei klinischem Verdacht auf eine koexistente AIH oder Steatohepatitis [18]. Auch die Sarkoidose der Leber kann sich unter dem Bild einer cholestatischen Lebererkrankung manifestieren. Die Sarkoidosegranulome besitzen jedoch meist keinen unmittelbaren Bezug zu Gallengängen, der cholangiopathische Effekt ist durch die Einbeziehung der Gallengänge in den Verfaserungsprozess bedingt [48].

\section{Primäre sklerosierende Cholangitis}

Die PSC ist eine mutmaßlich immunmediierte chronische Gallenwegserkrankung gekennzeichnet durch Entzündung, Fibrose und Zerstörung intrahepatischer und/oder extrahepatischer Gallengänge gefolgt von Cholestase, Gallengangsstrikturen, hepatischer Fibrose bis zur biliären Zirrhose [8, 25, 48]. Etwa $33-88 \%$ der PSC gehen mit pANCA oder anderen Autoantikörpern im Serum einher [25]. Diese Autoantikörperbefunde besitzen keine diagnostische Spezifität. Drei Viertel aller Patienten sind jünger als 50 Jahre, auch Neugeborene und Kinder können betroffen sein. Es dominiert das männliche Geschlecht in einer Relation von 2-3:1. Die Inzidenz beträgt etwa 1/100.000 per anno. Von 7121 Patienten wurden nach im Median von 14,4 Jahren als Endpunkte eine Lebertransplantation (1696 Patienten), 


\section{Schwerpunkt: Leberpathologie}

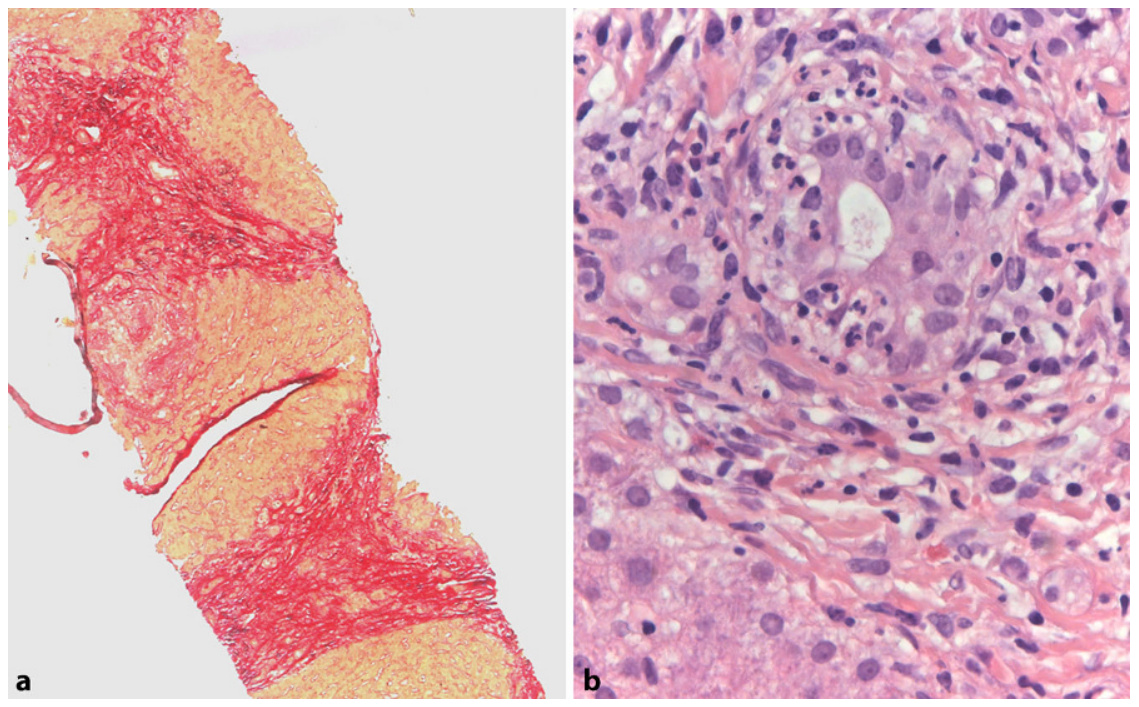

Abb. 8 \ Sklerosierende Cholangitis mit granulozytären epithelialen Läsionen (GEL). a Portalfelder verbindende Fibrosklerose. b GEL eines interlobulären Gallenganges; keine Granulozyten in der Lichtung. Rundzellige Infiltration und Fibrose des Portalfeldes (Klinik: 6 Jahre, m, AST $128 \mathrm{U} / \mathrm{l}, \mathrm{GGT} 304 \mathrm{U} / \mathrm{l}$, LKM Typ 1 [Autoantikörper gegen Leber-Nieren-Mikrosomen] 1:3200, pANCA 1:80)
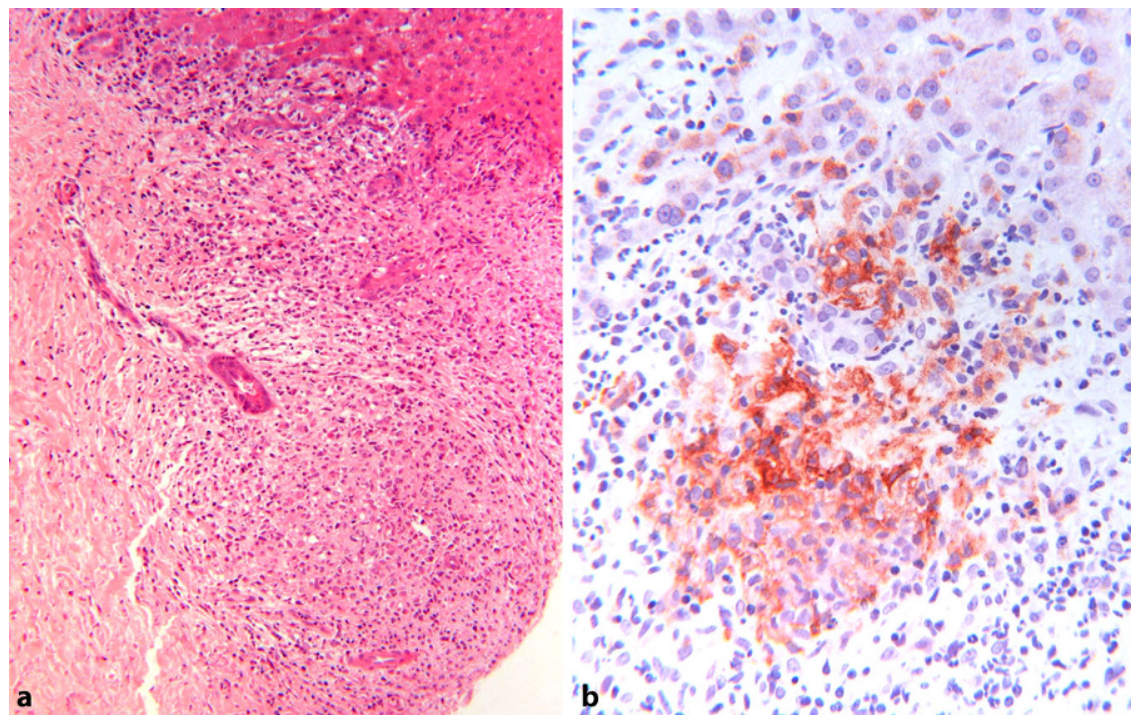

Abb. 9 A Langerhans-Zell-Histiozytose (LHC). a Mit nahezu granulomatöser Destruktion eines Gallenganges in sklerosiertem Portalfeld. b CD1a-positive Langerhans-Zell-Infiltrate (19 Jahre, w, bekannte LHC mit Befall des Felsenbeines)

Tod an der Erkrankung ohne Lebertransplantation (920 Patienten) und bei 721 ein Karzinom des hepatobiliären und pankreatischen Systems dokumentiert, hierunter 594 Cholangiokarzinome [44].

Die PSC wird anhand eines cholestatischen Leberenzymmusters in Kombination mit typischen bildgebenden Befunden bevorzugt unter Einsatz der MRCP diagnostiziert. Die Leberbiopsie ist in diesen Fällen nicht erforderlich [8, 25 , 37]. Die ERCP kommt zur Gewin- nung von Gewebe- oder Zellmaterial aus den Gallengängen zum Einsatz [8].

Die Small-Duct-PSC ist als Variante durch ein cholestatisches Leberenzymbild, histologische Kennzeichen der PSC und unauffällige extrahepatische Gallengänge in bildgebenden Befunden gekennzeichnet [48]. Diese ca. 4-10\% betreffende Sonderform geht mit einem günstigeren Verlauf und einem sehr viel niedrigeren Risiko eines Cholangiokarzinoms einher [44]. Die Leberbiopsie ist zur Diagnosestellung der Small-DuctPSC, der Overlapsyndrome wie auch zur Klärung unklarer Cholangiopathien anderer Ursache indiziert $[8,25,37]$.

Histologische Befunde der PSC. Die präformierten Gallengänge sind von einer konzentrischen zwiebelschalenartigen Ödemfibrose betroffen, die mit lockerem lymphoplasmazellulärem Infiltrat assoziiert sein kann (•Abb.6). Dieses peribiliäre Fibrosemuster kann auch bei sekundären fibrosierenden Cholangiopathien auftreten und ist somit nicht spezifisch für die PSC. Degenerative Epithelveränderungen mit Apoptosen, in kleinen Gängen mit unregelmäßig über die Zirkumferenz verteilten Zellkernen (-Abb. 11b) und manchmal Metaplasien in Form biliärer Hepatozyten treten hinzu. Als Grundlage werden wie bei der $\mathrm{PBC}$ eine deregulierte Autophagie und aktivierte Seneszenzmechanismen in den Cholangiozyten vermutet, die sekundär das peribiliäre Gewebemilieu verändern [32]. Folge fortschreitender Degeneration ist die zellarme fibröse Verödung früherer Gangabschnitte (• Abb. 7). Umgebende Portalfeldbereiche enthalten wechselnd dichte lymphoplasmazelluläre Infiltrate. Eine Sklerosierung des gesamten Portalfeldes und portale venolitische Veränderungen können hinzutreten. Eine lineare Verbreiterung der biliären Basalmembran, sichtbar insbesondere in der PAS-Färbung, kann um kleine interlobuläre Gallengänge beobachtet werden (ब Abb. 7; [9]). Im periportalen Leberparenchym können als Zeichen der Cholestase eine fedrige Parenchymzelldegeneration, MalloryDenk-Körper, Anreicherung von Kupfer und kupferbindendem Protein in Hepatozyten hinzutreten. Die Stadieneinteilung der PSC erfolgt in 4 Stufen ähnlich wie bei der PBC [27]. Da die PSC zumeist ungleich im Lebergewebe voranschreitet, liegen oft unterschiedliche Stadien nebeneinander vor.

Die sklerosierende Cholangitis mit granulozytären epithelialen Läsionen wurde als Sonderform einer primären sklerosierenden Cholangitis oder Variante der PSC herausgearbeitet [46]. Bei ihr sind neben einer gemischtzelligen portalen Entzündung mit Interfaceaktivität und 


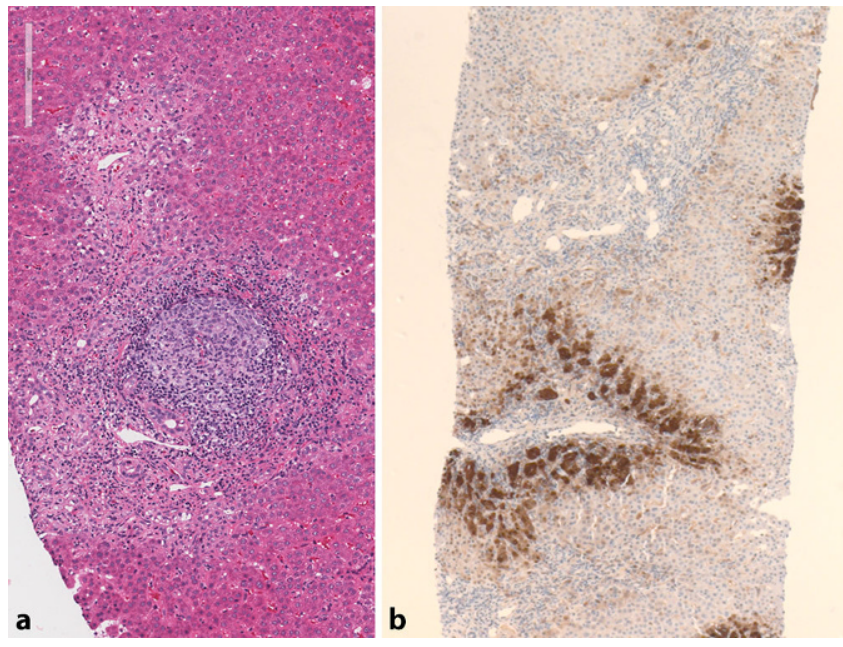

Abb. $10 \triangle$ Autoimmunhepatitis(AlH)-primäre-sklerosierende-Cholangitis(PSC)-Overlap. a AlH-Komponente mit Lymphfollikel, Grenzflächenhepatitis und portozentraler Ausfallstraße. b Die Glutaminsynthetasereaktion umgrenzt einen perivenolären Ausfallbereich (Klinik: 16 Jahre, m, GPT $313 \mathrm{U} / \mathrm{i}, \mathrm{GGT}$ $934 \mathrm{U} / \mathrm{l}, \mathrm{ANA}>1: 1600, \mathrm{lgG} 20 \mathrm{mg} / \mathrm{dl}$ )
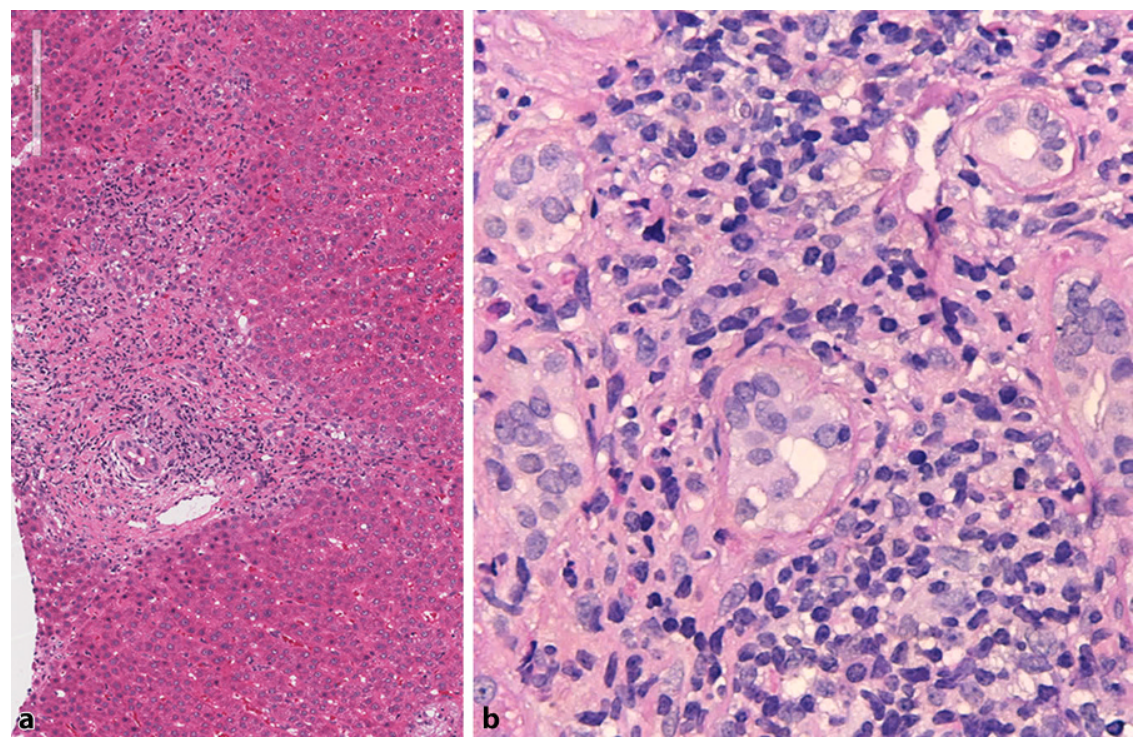

Abb. $11 \triangle$ Autoimmunhepatitis(AlH)-primäre-sklerosierende-Cholangitis(PSC)-Overlap (gleicher Fall wie - Abb. 10). a PSC-Komponente mit degenerativ verändertem interlobulärem Gallengang in fibrosierter portaler Matrix. b Lymphozytäres Infiltrat um degenerativ veränderte Gangtapete mit ungleich verteilten Zellkernen, Apoptose, Zytoplasmavakuolen und deutlich sichtbarer biliärer Basalmembran

periportaler Fibrose (•Abb. 8a) granulozytäre epitheliale Läsionen (GEL) der histologische Leitbefund. GEL sind durch eine fokale extensive Infiltration der Epitheltapete präformierter Gallengänge durch neutrophile Granulozyten gekennzeichnet gefolgt von Disruptionen des Gangepithels ( $\bullet$ Abb. 8b). Diese Cholangitisform findet ihre histologische Analogie in der autoimmunen Pankreatitis Typ 2 und kann mit einem Morbus Crohn vergesellschaftet sein. Das gute
[37]. Eine wichtige Differenzialdiagnose der PSC im Kindes- und Jugendalter ist die Langerhans-Zell-Histiozytose, die hepatisch bevorzugt Gallengänge affektiert und mit granulomartigen Infiltraten und insbesondere gallengangsverödenden Sklerosen einhergeht (• Abb. 9a; [40]). Eosinophil-granulozytäre Infiltrate sowie die Expression von Langerin, CD1a (- Abb. 9b) und S100-Protein in den atypischen Histiozyten sind diagnostisch wegweisend. Weiterhin abzugrenzen sind sekundäre sklerosierende Cholangitiden, schließlich das entlang der Portalfelder ausgebreitete, nichtmassebildende Cholangiokarzinom [48].

\section{Overlapsyndrome}

Hierunter fallen autoimmune Lebererkrankungen mit klinischen, serologischen, immunserologischen und histologischen Schnittmengenbefunden zwischen AIH und PBC oder AIH und PSC (• Tab. 5; [5]). Ein Overlap zwischen PBC und PSC ist nur für Einzelfälle beschrieben [17]. Die Schnittmengenbefunde sind nicht standardisiert definiert $[5,17]$.

AIH-PBC-Overlap-Befunde sollen histologisch neben floriden Gallengangsläsionen als Zeichen der PBC auch eine signifikante lymphozytäre Interfaceaktivität als Zeichen einer AIH-Komponente aufweisen. Geringe Grenzflächenaktivität im Rahmen einer PBC reichen nicht zur Diagnose eines AIH-PBC-Overlapsyndroms aus. Die Diagnose von AIH-PBC-Overlapsyndromen hat therapeutische Relevanz: Die mit Ursodesoxycholsäure therapierte $\mathrm{PBC}$ bedarf keiner zusätzlichen Steroidbehandlung, die die Osteoporoseneigung der PBCPatienten verstärken würde. Andererseits lässt sich der Progress der Fibrose bei einem AIH-PBC-Overlapsyndrom durch eine Steroidtherapie hemmen.

Beim AIH-PSC-Overlapsyndrom sind als PSC-Komponente die großen und/oder kleinen Gallengänge beteiligt. In letzterem Falle kann die Diagnose gegebenenfalls an der Biopsie gestellt werden. Bei Kindern firmiert dieses Krankheitsbild auch unter dem Begriff der autoimmunen sklerosierenden Cholangitis (AISC, ASC) ([28, 37]; • Abb. 10 


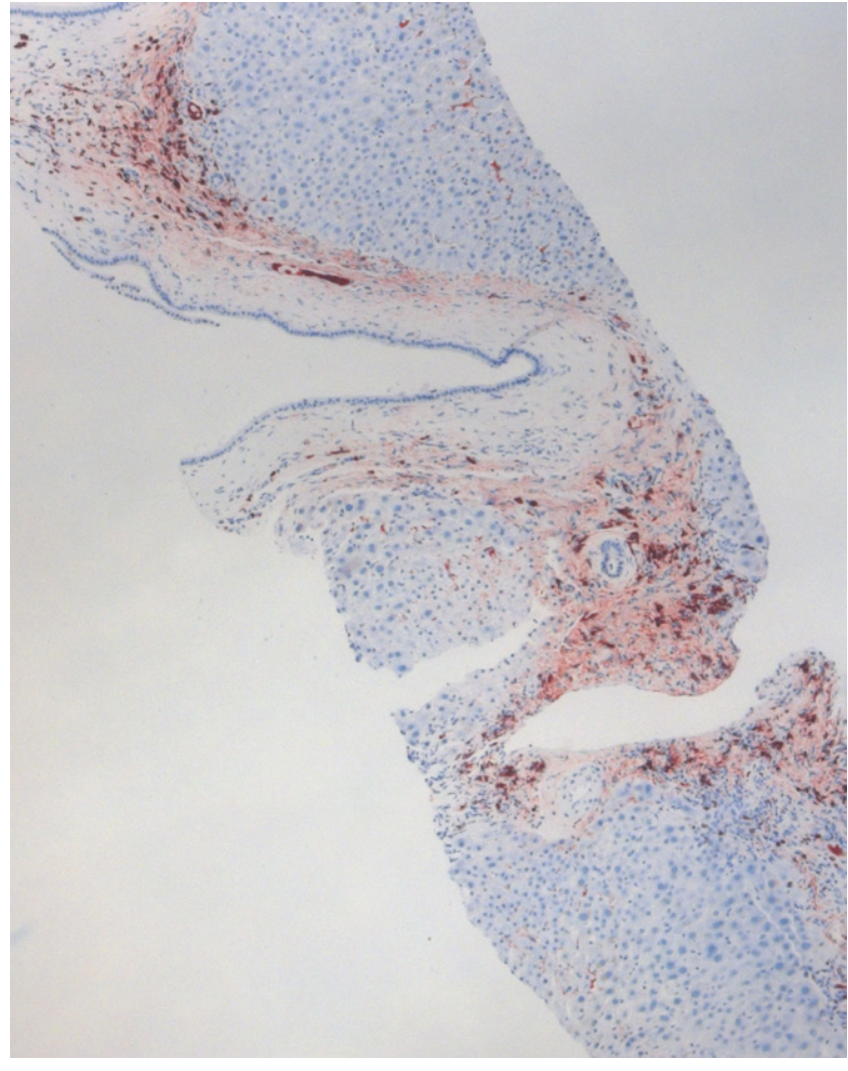

Abb. $12 \triangleleft \operatorname{lgG} 4-$ assoziierte Lebererkrankung mit portalfeldverbindender biliärer Fibrose, periduktaler Fibrose und Infiltration durch IgG4-exprimierende Plasmazellen, $>20$ pro HPFx40

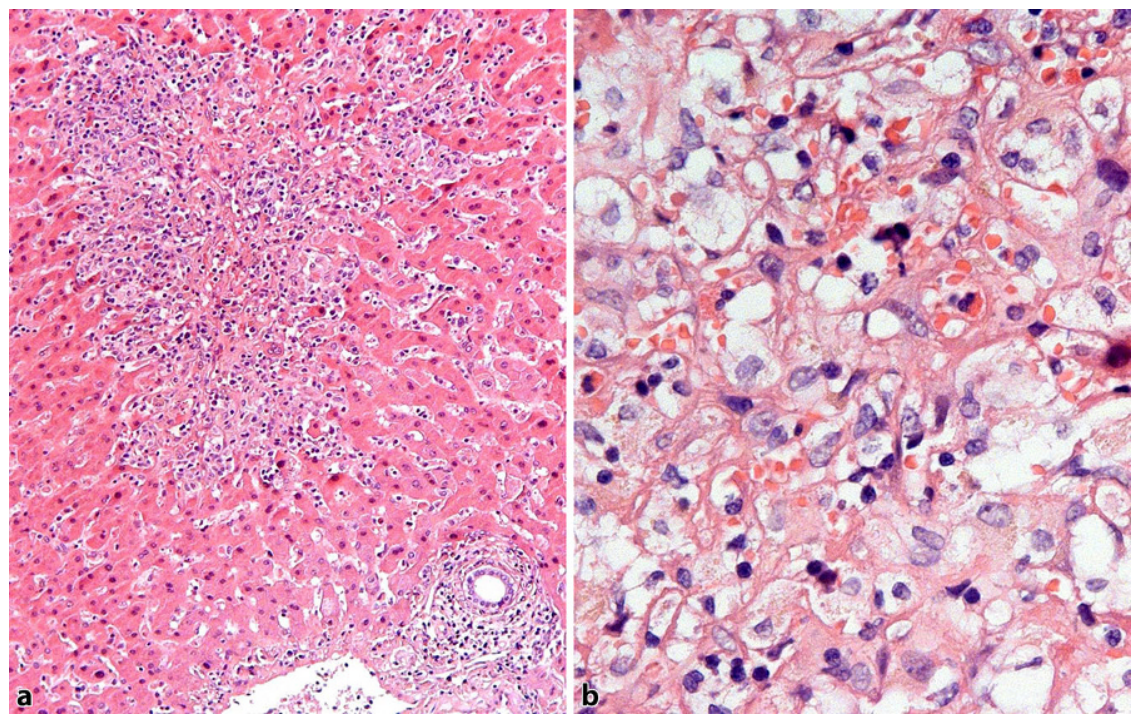

Abb. $13 \Delta$ Reaktives hämophagozytisches Syndrom. a Mit läppchenzentral akzentuiertem Parenchymausfall und T-Zell-reicher Infiltration (obere Bildhälfte). $\mathbf{b}$ Makrophagenaktivierung und Erythrophagozytose im Ausfallbereich (29 Jahre, w, Polyserositis, wechselnde Gelenkbeschwerden, sich anbahnendes Leberversagen; in Kindheit chronische Polyarthritis; Befundnormalisierung unter Kortison)

und 11). Die Erkrankung ist in frühen Stadien steroidresponsibel, ist aber im Langzeitverlauf prognostisch ungünstiger als die reine $\mathrm{AIH}$, wenn die therapierefraktäre PSC fortschreitet [28].

\section{IgG4-assoziierte Erkrankungen}

Die IgG4-assoziierte Erkrankung kann sich als systemische, chronische, fibroinflammatorische Entzündung mit zahlreichen IgG4-positiven Plasmazellen und erhöhtem IgG4-Spiegel im Serum in na- hezu allen Organen manifestieren, so als autoimmune Pankreatitis Typ 1, weiterhin in den Gallenwegen, den Speicheldrüsen, seltener in der Leber [15]. Bezogen auf die Leber sind zu unterscheiden:

Der hepatische lymphoplasmozytische inflammatorische Pseudotumor - er ist durch eine storiforme fibroblastäre Herdentzündung mit dominierendem lymphoplasmozytischem Infiltrat einschließlich zahlreicher IgG4-exprimierender Plasmazellen und obliterierenden Phlebitis gekennzeichnet und gegenüber dem fibrohistiozytischen inflammatorischen Pseudotumor und inflammatorischen Spindelzellneoplasien abzugrenzen [40].

Die IgG4-assoziierte sklerosierende Cholangitis [15, 47, 48] - diese ist in 95\% der Fälle mit einer Pankreatitis Typ I assoziiert, seltener mit anderen Manifestationen einer IgG4-assoziierten Erkrankung wie Sialadenitis, Dakryoadenitis oder retroperitonealer Fibrose. Sie betrifft insbesondere Männer älter als 50 Jahre, besitzt somit ein höheres Manifestationsalter als die PSC. Sie führt $\mathrm{zu}$ einer storiformen Fibrose mit lymphoplasmazellulären Infiltraten um große Gallengänge, die im Gegensatz zur PSC eine intakte Epitheltapete aufweisen. Im Bereich peripherer Portalfelder bzw. in der Leberbiopsie sind diese Infiltrate um kleine Gallengänge ausgerichtet, weisen aber im Gegensatz zur PSC keine fibroobliterierende Gangsklerose auf (- Abb. 12). Eine portale Venolitis sowie eine Vermehrung IgG4-exprimierender Plasmazellen auf $>10 /$ HPF sind weitere Bausteine der Diagnose [15, 37]. Die Vermehrung IgG4-exprimierender Plasmazellen oder erhöhte IgG4-Werte im Serum als einzige Befunde reichen zur Diagnose nicht aus.

Die IgG4-assoziierte autoimmune Hepatitis, erstmals beschrieben von Umemura et al. [41], erfüllt die histologischen Kriterien einer autoimmunen Hepatitis und ist zudem durch eine vermehrte Infiltration durch IgG4-exprimierende Plasmazellen und erhöhte IgG4Serumspiegel gekennzeichnet [42]. Legt man als diagnostische Kriterien für die IgG4-AIH den Nachweis von mindestens 10 IgG4-positive Plasmazellen/HPF in Kombination erhöhter Serum-IgG4- 
Tab. 5 Klinisch-pathologische Befunde bei Varianten autoimmuner Lebererkrankungen. (Nach Washington et al. [43])

\begin{tabular}{|c|c|c|}
\hline & AlH-PBC-Overlap & AIH-PSC-Overlap \\
\hline Alter & $50-60$ & Kinder, 30-40 \\
\hline Geschlecht & $w \gg m$ & $\mathrm{~m}>\mathrm{w}$; bei Kindern $\mathrm{m}=\mathrm{w}$ \\
\hline Autoantikörper & $\begin{array}{l}\text { ANA, SMA, LKM, SLA/LP } \\
\text { AMA-PDHE2 }\end{array}$ & ANA, pANCA \\
\hline $\begin{array}{l}\text { Biochemische } \\
\text { Tests }\end{array}$ & $\begin{array}{l}\text { Transaminasen, AP, GGT, Im- } \\
\text { munglobuline erhöht }\end{array}$ & $\begin{array}{l}\text { Transaminasen, AP, GGT erhöht; bei Kindern } \\
\text { Immunglobuline erhöht }\end{array}$ \\
\hline \multicolumn{3}{|c|}{$\begin{array}{l}\text { AIH Autoimmune Hepatitis, ANA antinukleäre Antikörper, } A P \text { alkalische Phosphatase, GGT Gam- } \\
\text { ma-Glutamyltransferase, LKM Liver-Kidney-Mikrosomen-Antikörper, pANCA antineutrophile cyto- } \\
\text { plasmatische Antikörper mit perinukleärem Muster, } P B C \text { primäre biliäre Cholangitis, PSC primäre } \\
\text { sklerosierende Cholangitis, SLA/LP lösliches Leberantigen/Leber-Pankreas-Antikörper, SMA glatt- } \\
\text { muskuläre Antikörper }\end{array}$} \\
\hline
\end{tabular}

Spiegel zugrunde [33], ist diese Entzündung sehr selten. Sie wird auch bei Kindern beobachtet. Hinsichtlich der Leberenzymverschiebung im Serum und dem Auftreten von ANA unterscheiden sich IgG4-AIH und klassische AIH nicht. Sie scheint rasch auf eine Corticoidtherapie anzusprechen. Ob die IgG4-AIH ein Subtyp der AIH darstellt oder dem Spektrum der systemischen IgG4-assoziierten Erkrankung zuzurechnen ist, ist noch nicht abschließend geklärt [17, 29].

\section{Mitbeteiligung der Leber im Zusammenhang mit extrahepatischen Autoimmun- erkrankungen}

Ein breites Spektrum primär extrahepatischer autoimmuner Erkrankungen kann bei AIH zeitgleich oder sequenziell beobachtet werden, insbesondere rheumatoide Arthritis, Autoimmunsialadenitis, systemischer Lupus erythematodes [17, 37].

Hashimoto-Thyreoiditis und SjögrenSyndrom begleiten nicht selten die PBC. Bei etwa 60-80 \% der PSC in Nordeuropa und Nordamerika findet sich eine metaoder synchrone chronische entzündliche Darmerkrankung, meist Colitis ulcerosa, seltener ein Morbus Crohn. Etwa 3\% der Colitis-ulcerosa-Fälle sind mit einer PSC assoziiert [37].

Zöliakie und autoimmune Lebererkrankungen: Bei 39-47\% erwachsener und $26-57 \%$ pädiatrischer Zöliakiepatienten werden erhöhte Transaminasen beobachtet. Die hepatitischen Veränderungen in der Leberbiopsie sind meist gering und unter glutenfreier Diät re- versibel [3]. Einzelfälle einer schweren entzündlichen Lebererkrankung bis zur Zirrhose sind beschrieben. Bei Zöliakie besteht ein 4- bis10fach erhöhtes Risiko für spezifische autoimmune Lebererkrankungen wie AIH, PBC und PSC [4].

Die noduläre regeneratorische Hyperplasie kann im Rahmen verschiedener immunologischer Grunderkrankungen so bei schwerer rheumatoider Arthritis bzw. dem Felti-Syndrom wie auch im Rahmen des Antiphospholipidsyndroms beobachtet werden. Für diesen nichtzirrhotischen mikronodulären Leberumbau werden entzündlich-obliterative Veränderungen kleiner Portalvenenäste verantwortlich gemacht. Aber auch eine endotheliotoxische Wirkung von Azathioprin, eine häufige Komponente der AIH-Therapie, kann eine pathogenetische Rolle spielen [4].

Das reaktive hämophagozytische Syndrom (rHS) bzw. Makrophagenaktivierungssyndrom ist durch eine reaktive Histiozytenproliferation mit Phagozytose von Hämatopoesezellen und durch eine ausgeprägte T-Zell-Aktivierung und mit exzessiver Bildung proinflammatorischer Zytokine, dem „Zytokinsturm“ gekennzeichnet. Vor dem Hintergrund einer Autoimmunerkrankung wird das rHS insbesondere im Rahmen der juvenilen Form der rheumatoiden Arthritis (Morbus Still) [7, 10] oder bei Kollagenosen wie dem Lupus erythematodes beschrieben. Histologisch steht die Hyperplasie sinusoidaler Histiozyten mit Erythrophagozytose im Vordergrund (• Abb. 13). Hinzutreten können Leberzellnekrosen, makrovesikuläre Steatose, lobuläre Granulome und ein hepatitisches Bild mit Leberzellnekrosen bis zu einer schweren entzündlichen Leberschädigung. Der Schwerpunkt der Entzündung liegt im Gegensatz zur AIH im Leberparenchym, Gallengangsaffektion und Piecemealnekrosen stehen im Hintergrund ([13]; • Abb. 13). Für die Therapie ist es zwingend erforderlich, zwischen infektionsassoziierten rHS und rHS im Rahmen einer autoimmunen Grunderkrankung zu unterscheiden. Letztere sind mit Kortikoiden und gegebenenfalls ergänzenden Immunsuppressiva anzugehen. Bei ersteren hingegen steht die Behandlung der zugrunde liegenden Infektion im Vordergrund.

\section{Beziehungen zwischen autoimmuner Lebererkrankung und medikamenteninduzierter Leberschädigung}

Es lassen sich 3 Möglichkeiten unterscheiden [17]:

- Eine Medikamentenunverträglich-

keit, die eine AIH imitiert. Die zugrunde liegende immunallergische Reaktion kann serologisch mit einer Hypergammaglobulinämie, ANA und ASMA einhergehen und histologisch durch eine portal/periportale Infiltration durch Lymphozyten, Plasmazellen, eosinophile Granulozyten, im Verlauf durch periportale und portozentrale Brückenfibrosen gekennzeichnet sein.

- Eine Medikamentenunverträglichkeit, die eine zusätzliche AIH verdeckt.

- Eine AIH, die medikamentös induziert wird. Hierfür bekannte Medikamente sind u. a. Nitrofurantoin und Minocyclin, des weiteren alphaMethyldopa, Clometacin, Statine, Interferon, TNF-alpha-Antagonisten.

Die histomorphologische Schnittmenge zwischen genuiner AIH und medikamentös induzierter Leberschädigung (DILI) ist groß. Stärkere portale, periportale und lobuläre Entzündungsaktivität, der Plasmazellreichtum portal und lobulär, Leberzellrosetten und Emperipolese sprechen eher für eine $\mathrm{AIH}$, während neutrophil-granulozytäre Infiltrate und 
Schwerpunkt: Leberpathologie

\begin{tabular}{|c|c|}
\hline \multicolumn{2}{|c|}{ Abkürzungen } \\
\hline$A I H$ & Autoimmunhepatitis \\
\hline AISC, ASC & $\begin{array}{l}\text { Autoimmune sklerosierende } \\
\text { Cholangitis }\end{array}$ \\
\hline$A L T$ & Alanin-Aminotransferase \\
\hline AMA & $\begin{array}{l}\text { Antimitochondriale Antikör- } \\
\text { per }\end{array}$ \\
\hline$A M A-P D C-E 2$ & $\begin{array}{l}\text { Antimitochondriale Antikör- } \\
\text { per gegen E2-Untereinheit } \\
\text { des Pyruvathydrogen- } \\
\text { asekomplexes bzw. AMA } \\
\text { M2a }\end{array}$ \\
\hline ANA & Antinukleäre Antikörper \\
\hline$A P$ & Alkalische Phosphatase \\
\hline APECED & $\begin{array}{l}\text { Autoimmune Polyendokri- } \\
\text { nopathie-Candidiasis-ecto- } \\
\text { dermale Dystrophie }\end{array}$ \\
\hline AST & Aspartat-Aminotransferase \\
\hline DILI & $\begin{array}{l}\text { Arzneimittelinduzierter Le- } \\
\text { berschaden, "drug-induced } \\
\text { liver injury“ }\end{array}$ \\
\hline$E R C P$ & $\begin{array}{l}\text { Endoskopische retrograde } \\
\text { Cholangiopankreatikoko- } \\
\text { grafie }\end{array}$ \\
\hline GEL & $\begin{array}{l}\text { Granulozytäre epitheliale } \\
\text { Läsionen }\end{array}$ \\
\hline GGT & Gamma-Glutamyltransferase \\
\hline GOT & $\begin{array}{l}\text { Glutamat-Oxalacetat-Trans- } \\
\text { aminase, entspricht AST }\end{array}$ \\
\hline GPT & $\begin{array}{l}\text { Glutamat-Pyruvat-Transami- } \\
\text { nase, entspricht ALT }\end{array}$ \\
\hline$g p 210$ & $\begin{array}{l}\text { Nukleäres Glycoprotein } \\
210 \text { (Bestandteil des } \\
\text { Kernporenkomplexes) }\end{array}$ \\
\hline$L C-1$ & $\begin{array}{l}\text { Antikörper gegen Leberzy- } \\
\text { tosolprotein Typ } 1\end{array}$ \\
\hline$L K M$ & $\begin{array}{l}\text { Antikörper gegen Leber- } \\
\text { Nieren-Mikrosomen }\end{array}$ \\
\hline$L P$ & $\begin{array}{l}\text { Antikörper gegen Le- } \\
\text { ber-Pankreas-Antigen }\end{array}$ \\
\hline$m H A I$ & $\begin{array}{l}\text { Modifizierter Hepatitis-Akti- } \\
\text { vitätsindex }\end{array}$ \\
\hline$M R C P$ & $\begin{array}{l}\text { Magnetresonanz-Cholan- } \\
\text { giopankreatikografie }\end{array}$ \\
\hline PANCA & $\begin{array}{l}\text { Antineutrophile zytoplas- } \\
\text { matische Antikörper mit } \\
\text { perinukleärem Muster }\end{array}$ \\
\hline$P B C$ & Primäre biliäre Cholangitis \\
\hline PSC & $\begin{array}{l}\text { Primäre sklerosierende } \\
\text { Cholangitis }\end{array}$ \\
\hline
\end{tabular}

\begin{tabular}{|ll}
\hline Abkürzungen & (Fortsetzung) \\
\hline$S L A$ & $\begin{array}{l}\text { Antikörper gegen lösliches } \\
\text { Leberantigen }\end{array}$ \\
\hline$S M A$ & $\begin{array}{l}\text { Antikörper gegen glatte } \\
\text { Muskulatur }\end{array}$ \\
\hline
\end{tabular}

hepatozelluläre Cholestase eher bei DILI zu finden sind [38].

AIH-ähnliche Medikamentenreaktionen sprechen wie eine AIH auf eine hoch dosierte Steroidtherapie an. Bleibt nach Absetzen des kritischen Medikamentes und Zurückfahren der Steroidtherapie ein Rückfall der Erkrankung aus, spricht dies für eine hepatitisartige Medikamentenreaktion [17]. Zur Prüfung auf mögliche Medikamententoxizität helfen Datenbanken, z. B. NIH LiverTox Database, orientierend weiter.

Bei der der bioptischen Diagnostik autoimmuner Lebererkrankungen ist die vertrauensvolle Zusammenarbeit mit einem kompetenten klinischen Partner ein wichtiger Diagnosebaustein.

\section{Fazit für die Praxis}

- Die Autoimmunhepatitis (AlH) geht im typischen Fall mit Autoantikörperbefunden im Serum, einer Hypergammaglobulinämie vom Typ IgG und kennzeichnenden histopathologischen Merkmalen einher.

- Die histologisch kennzeichnenden Befunde sind das Bild einer chronischen Hepatitis mit plasmazellreicher dominierender Grenzflächenaktivität, Rosettierung der Hepatozyten und Emperipolese. Diese Befunde gehen in die interdisziplinären Scoringsysteme zur AlH-Diagnose ein. Damit ist die Leberbiopsie ein integraler Bestandteil der AlHDiagnostik.

- Entsprechend den unterschiedlichen Verlaufsformen kann sich die AlH auch mit varianten histologischen Befunden so dem Bild einer subakuten Dystrophie oder einer akuten Hepatitis oder Leberzirrhose primär manifestieren.

- Die primäre biliäre Cholangitis (PBC) betrifft vornehmlich Frauen des mittleren Lebensalters, geht mit antimi- tochondrialen Autoantikörpern oder besonderen antinukleären Antikörpern einher und befällt ausschließlich intrahepatische Gallengänge im typischen Falle in Form chronischer, nichteitriger, destruierender Gallengangsläsionen.

- Die primäre sklerosierende Cholangitis (PSC) betrifft vornehmlich jüngere Männer, aber auch Kinder, kann mit uncharakteristischen Autoantikörperbefunden einhergehen und befällt extra- und/oder intrahepatische Gallengänge. Histologischer Schlüsselbefund ist die zwiebelschalenartige periduktale Fibrose bis zur verödenden Gangsklerose. Die SmallDuct-PSC betrifft ausschließlich intrahepatische Gallengänge.

- Als Overlapsyndrome werden histopathologische Schnittmengenbefunde aus AIH und PBC oder AIH und PSC bezeichnet.

- Medikamenteninduzierte Leberschädigungen können mit für eine $\mathrm{AlH}$ typischen immunserologischen Befunden einhergehen und histologisch eine AlH imitieren oder eine AlH induzieren oder eine vorbestehende AlH überdecken.

- Der Leberbiopsie kommt eine gewichtige Rolle zu bei der Diagnose der AlH und ihrer Varianten, der SmallDuct-PSC, der AMA-negativen PBC, der IgG4-assoziierten Entzündungen und der Abgrenzung gegenüber konkurrierenden Lebererkrankungen, insbesondere der medikamentöstoxischen Leberschädigung.

\section{Korrespondenzadresse}

\section{Prof. Dr. Hans-Peter Fischer}

Institut für Pathologie, Universität Bonn

Venusberg-Campus 1, 53127 Bonn,

Deutschland

hans-peter.fischer@ukbonn.de

\section{Einhaltung ethischer Richtlinien}

Interessenkonflikt. H.-P. Fischer und D. Goltz geben an, dass kein Interessenkonflikt besteht.

Für diesen Beitrag wurden von den Autoren keine Studien an Menschen oder Tieren durchgeführt. Für die aufgeführten Studien gelten die jeweils dort angegebenen ethischen Richtlinien. 
Open Access. Dieser Artikel wird unter der Creative Commons Namensnennung 4.0 International Lizenz veröffentlicht, welche die Nutzung, Vervielfältigung, Bearbeitung, Verbreitung und Wiedergabe in jeglichem Medium und Format erlaubt, sofern Sie den/die ursprünglichen Autor(en) und die Quelle ordnungsgemäß nennen, einen Link zur Creative Commons Lizenz beifügen und angeben, ob Änderungen vorgenommen wurden.

Die in diesem Artikel enthaltenen Bilder und sonstiges Drittmaterial unterliegen ebenfalls der genannten Creative Commons Lizenz, sofern sich aus der Abbildungslegende nichts anderes ergibt. Sofern das betreffende Material nicht unter der genannten Creative Commons Lizenz steht und die betreffende Handlung nicht nach gesetzlichen Vorschriften erlaubt ist, ist für die oben aufgeführten Weiterverwendungen des Materials die Einwilligung des jeweiligen Rechteinhabers einzuholen.

Weitere Details zur Lizenz entnehmen Sie bitte der Lizenzinformation auf http://creativecommons.org/ licenses/by/4.0/deed.de.

\section{Literatur}

1. Abe K, Takahashi A, Nozawa Yetal (2014) The utility of IgG, IgM, and CD138 immunohistochemistry in the evaluation of autoimmune liver disease. Med Mol Morphol 47:162-168

2. Alvarez F, Berg PA, Bianchi FB, Bianchi L, Burroughs AK, Cancado EL, Chapman RW et al (1999) International Autoimmune Hepatitis Group Report: review of criteria for diagnosis of autoimmune hepatitis. J Hepatol 31:929-938

3. Anania C, De Luca E, De Castro G, Chiesa C, Paficio L (2015) Liver involvement in pediatricceliac disease. World J Gastroenterol 21:5813-5822

4. Bellamy C, Burt AD (2018) The liver in systemic disease. In: Burt AD, Portmann BC, Hübscher SG (Hrsg) MacSween's pathology of the liver, 7. Aufl. Churchill Livingstone, Edinburgh, S966-1018

5. Boberg KM, Chapman RW, Hirschfield GM, Lohse AW, Manns MP, Schrumpf E (2011) Overlap syndromes: the International Autoimmune Hepatitis Group (IAIHG) position statement on a controversial issue. J Hepatol 54:374-385

6. de Boer YS, van Nieuwkerk CM, Witte BI, Mulder CJ, Bouma G, Bloemena E (2015) Assessment of the histopathological key features in autoimmune hepatitis. Histopathology 66:351-362

7. Bruck N, Schnabel A, Hendrich CM (2015) Current understanding of the pathophysiology of systemic juvenile idiopathic arthritis (sJA) and targetdirected therapeutic approaches. Clin Immunol 159:72-83

8. Chapman MH, Thorburn D, Hirschfield GM, Webster GGJ, Rushbrook SM, Alexander G, Collier J, Dyson JK, Jones DEJ, Patanwala I, Thain C, Walmsley M, Pereira SP (2019) British Society of Gastroenterology and UK-PSC guidelines for the diagnosis and management of primary sclerosing cholangitis. Gut 68:1356-1378

9. Colling R, Verrill C, Frier Eetal (2016) Bile duct basement membrane thickening in primary sclerosing cholangitis. Histopathology 68:816-842

10. Cortis E, Insalaco A (2006) Macrophage activation syndrome in juvenile idiopathic arthritis. Acta Paediatr Suppl 95:38-41

11. Couto CA, Bittencourt PL, Porta G et al (2014) Antismooth muscle and antiactin antibodies are indirect markers of histological and biochemical activity of autoimmune hepatitis. Hepatology 59:592-600

12. Dahlan Y,SmithI,Simmonds D, Jewell LD, Wanless I, Heatthcote EJ et al (2003) Pediatric onset primary biliary cirrhosis. Gastroenterology 125:1476-1479

13. De Kerguenec C, Hillaire S, Molinie V, Gardin C, Degott C, Erlinger S, Valla D (2001) Hepatic manifestations of hemophagocytic syndrome: a study of 30 cases. Am J Gastroenterol 96:854-857

14. Demetris AJ, Bellamy C, Hübscher SG et al (2016) 2016 Comprehensive update of the Banff Working Group on Liver allograft pathology: Introduction of amtibody-mediated rejection. Am J Transplant 16:2816-2835

15. Deshpande V, Sainani NI, Chung RT et al (2009) IgG4-associated cholangitis: a comparative histological and immunophenotypical study with primary sclerosing cholangitis on liver biopsy material. Mod Pathol 22:1287-1295

16. Deshpande V, Zen Y, Chan JKC et al (2012) Consensus statement on thepathology of IgG4related disease. Mod Pathol 25:1181-1192

17. EASL (2015) EASL clinical practice guidelines: Autoimmune hepatitis. J Hepatol 63:971-1004

18. EASL (2017) Clinical practice guidelines: the diagnosis and management of patients with primary biliary cholangitis. JHepatol 67:145-172

19. Estradas J, Pascual-Ramos V, Martinez B et al (2009) Autoimmune Hepatitis with giant cell transformation. Ann Hepatol 8:837-839

20. Gurung A, Assis DN, McCarty TR, Mitchell KA, Boyer JL, Jain D (2018) Histologic features of autoimmune hepatitis: a critical appraisal. Hum Pathol 82:51-60

21. Hennes EM, Zeniya M, Czaja A, Pares A, Dalekos GN Krawitt EL et al (2008) Simplified diagnostic criteria for autoimmune hepatitis. Hepatology 48:169-176

22. IshakK, Baptista A, Bianchil etal (1995) Histological grading and staging of chronic hepatitis. J Hepatol 22:696-699

23. Kerkar N, Vergani D (2018) De novo autoimmune hepatitis-is this different in adults compared to children? J Autoimmun 35:26-33

24. Lee H, Stapp RT, Ormsby AH, Shah VV (2010) The usefulness of IgG and IgM Immunostaining of periportal inflammatory cells (Plasma cells and lymphocytes) for the distinction of autoimmune hepatitis and primary biliary cirrhosis and their staining pattern in autoimmune hepatitis-primary biliary cirrhosis overlap syndrome. Am JClin Pathol 133:430-437

25. Lindor KD, Kowdley KV, Harrison ME (2015) ACG clinical guideline: primary sclerosing cholangitis. Am J Gastroenterol 110:646-659

26. Lintas C, Cappa M, Comparcola D, Nobili V, Fierabracci $A$ (2008) An 8-year-old boy with autoimmune hepatitis and Candida onychosis as the first symptoms of autoimmune polyglandular syndrome (APS1): identification of a new homozygous mutation in the autoimmune regulator gene (AIRE). Eur JPediatr 167:949-953

27. Ludwig J, La Russo NF, Wiesner RH et al (1986) Primary sclerosing cholangitis. In: Peters R, Craig JR (Hrsg) Liver pathology: contemporary issues in surgical pathology. Churchill Livingstone, New York, S193-213

28. Mieli-Vergani G, Vergani G, Baumann U, Czubkowski P, Debray D, Dezsofi A, Fischler B, Gupte G, Hierro L, Indolfi G, Jahnel J, Smets F, Verkade J, Hadzić N (2018) Diagnosis and management of pediatric autoimmune liver disease:ESPGHAN He- patology Commitee position statement. J Pediatr Gastroenterol Nutr 66:345-360

29. Minaga K, Watanabe T, Chung H, Kudo M (2019) Autoimmune hepatitis and lgG4-related disease. World J Gastroenterol 25:2308-2314

30. Nakamura M, Kondo H, Mori T, Komori A et al (2007) Anti-gp210 and Anti-Centromere antibodies are different risk factors for the progression of primary biliary cirrhosis. Hepatology 45:118-127

31. Nakanuma Y, Zen Y, Harada K et al (2010) Application of a new histologic staging and grading sytem for primary biliary cirrhosis to liver biopsy specimens: interobserver agreement. Pathol Int 60:167-174

32. NakanumaY, Sasaki M, Harada K(2015) Autophagie and senescence in fibrosing cholangiopathies. JHepatol 62:934-945

33. Nakanuma Y, Ishizu Y, Zen Y, Harada K, Umemura T (2016) Histopathology of IgG4-related autoimmune hepatitis and lgG4 related hepatopathy in lgG4 related disease. Semin Liver Dis 36:229-241

34. Ozaslan E, Efe C, Ozaslan NG (2016) The diagnosis of antimitochonrial antibody-negative primary biliary cholangitis. Clin Res Hepatol Gastroenterol 5:553-561

35. Portman B, Zen Y (2012) Inflammatory disease of the bile ducts-cholangiopathies: liver biopsy challenge and clinicopathological correlation. Histopathology 60:236-248

36. Scheuer PJ (1967) Primary biliary cirrhosis. Proc R SocMed 60:1257-1260

37. Strassburg CP, Beckebaum S, Geier A et al (2017) S2k Leitlinie Autoimmune Lebererkrankungen. ZGastroenterol 55:1135-1226

38. Suzuki A, Brunt EM, Kleiner DE, Miquel $R$, Smyrk TC, Andrade RJ, Lucena MI, Castiella A, Lindor K, Björnsson E (2011) The use of liver biopsy evaluation in discrimination of idiopathic autoimmune hepatitis versus drug-induced liver injury. Hepatology 54:931-939

39. Tiniakos DG, Brain JG, Bury YA (2015) Role of histopathology in autoimmune hepatitis. Dig Dis 33(suppl 2):53-64

40. Torbensen T, Zen Y, Yeh MM (2018) Tumors of the liver and intrahepatic bile ducts, 4. Aufl. Atlas of Tumor Pathology (AFIP Fascicle 27)

41. Umemura T, Hamano H, Kawa S, Nakanuma $Y$, Kiyosawa K (2007) Immunglobin G4-hepatopathy: association of immunglobin G4-bearing plasma cells in liver with autoimmune pancreatitis. Hepatology 46:463-471

42. Unemura $T$, Zen $Y$, Hamano $H$, Joshita $S$, Ichijo $T$, Yoshizawa K, Kiyosawa K, Ota M, Kawa S, Nakanuma Y, Tanaka E (2011) Clinical significance of immunoglobulin G4-associated autoimmune hepatitis. J Gastroenterol 46(Suppl):48-55

43. Washington MK, Manns MP (2018) Autoimmune hepatitis. In: Burt AD, Portmann BC, Hübscher SG (Hrsg) MacSween's pathology of the liver, 7. Aufl. Churchill Livingstone, Edinburgh, S491-514

44. Weismüller TJ, Trivedi PJ, Bergquist A, Imam M, Lenzen $\mathrm{H}$, Ponsioen $\mathrm{CY}$ et al (2017) Patient age, sex, and inflammatory bowel disease phenotype associate with course of primary sclerosing cholangitis. Gastroenterology 152:1975-1984

45. Yasui S, Fujiwara K, Yonemitsu Y, Oda S, Nakano M, Yokosuka O (2011) Clinicopathological features of severe and fulminant forms of autoimmune hepatitis. J Gastroenterol 46:378-390

46. Zen Y, Grammatikopoulos T, Heneghan MA, Vergani D, Mieli-Vergani G, Portman BC (2012) Sclerosing cholangitis with granulocytic epithelial lesion. A benign form of sclerosing cholangiopathy. Am J Surg Pathol 36:1555-1562 
47. Zen Y, Harada K, Sasaki M et al (2004) lgG4-related sclerosing cholangitis with and without hepatic inflammatory pseudotumor, and sclerosing pancreatitis associated sclerosing cholangitis: do they belong to a spectrum of sclerosing pancreatitis? Am J Surg Pathol 28:1193-1203

48. Zen Y, Hübscher SG, Nakanuma Y (2018) Bile duct diseases. In: Burt AD, Portmann BC, Hübscher SG (Hrsg) MacSween's pathology of the liver, 7. Aufl. Churchill Livingstone, Edinburgh, S515-593

\section{Bisher unbekannte Ursachen von Schilddrüsenkrebs entdeckt}

Unter Leitung der Universitätsmedizin Mainz hat ein internationales Forschungsteam eine Reihe von Proteinen als mögliche Ziele für Medikamente gegen Schilddrüsenkrebs identifiziert. Wie die Wissenschaftler in der Zeitschrift "Nature Communications“ berichten, könnten ihre Entdeckungen möglicherweise auch zur Entwicklung von Medikamenten für solche PTC-Patienten führen, denen bisher nur schwer geholfen werden kann.

Das sogenannte papilläre Schilddrüsenkarzinom (PTC) ist die häufigste Krebserkrankung der Schilddrüse. Mehrere Tausend Menschen in Deutschland erhalten jährlich diese Diagnose. Viele von innen können geheilt werden, bei einigen wirkt die entsprechende Standardbehandlung jedoch nicht. Ein internationales Forschungsteam unter Leitung der Universitätsmedizin Mainz hat nun bisher unbekannte Proteine und eine bisher unbekannte Fusion zweier Gene als Ursachen der Krankheit herausgefunden. Wie die Wissenschaftler in der Zeitschrift "Nature Communications" berichten, könnten ihre Entdeckungen möglicherweise auch zur Entwicklung von Medikamenten für solche PTC-Patienten führen, denen bisher nur schwer geholfen werden kann.

Das Team aus Wissenschaftlern mehrerer inund ausländischer Forschungseinrichtungen unter Leitung von Prof. Dr. Krishnaraj Rajalingam, Leiter der Cell Biology Unit der Universitätsmedizin Mainz, hatte mit einer Kombination verschiedener Methoden, darunter die sogenannte RNA-Sequenzierung, sämtliche Gene und Proteine in Tumorgewebe und gesundem Gewebe von Patienten mit dem papillären Schilddrüsenkarzinom untersucht. Bereits bekannt war, dass bei der Mehrzahl der Patienten mit dieser Krankheit eine Mutation eines der als BRAF und RAS bezeichneten Onkogene vorliegt. Ziel der Forscher war es, die Tumorentwicklung besser zu verstehen, die in Abwesenheit dieser häufigen Mutationen abläuft.

Als Forschungsansatz für ihre Analyse wählten die Forscher eine Kombination aus Proteomik- und Genomik-Technologien. Als Resultat fanden sie eine Reihe bisher unbekannter Proteine, welche die Entstehung von Tumoren fördern und sich deshalb als Ziele für mögliche neue Medikamente eignen. Im Erbgut eines Patienten entdeckten sie außerdem ein bisher unbekanntes TFG-
RET Fusionsprotein. Durch weitere Analysen stellten sie zudem fest, dass auch das durch die Fusion der beiden Gene TFG und RET gebildete Protein zur Entstehung von Tumoren führt und damit ebenfalls ein Ansatzpunkt für die Medikamentenentwicklung darstellt. Die Studie ist ein Ergebnis eines von der Deutschen Krebshilfe geförderten Forschungsprojekts von Prof. Dr. Krishnaraj Rajalingam zum Aufbau einer Sammlung von Gewebekulturen von Schilddrüsentumoren. Maßgeblich an dem Projekt beteiligt sind neben der Cell Biology Unit die Klinik für Allgemein-, Viszeral- und Transplantationschirurgie (AVTC) sowie das Institut für Pathologie der Universitätsmedizin Mainz.

"Die intensive Zusammenarbeit reicht von der Auswahl der Patienten über die Sammlung und Qualitätskontrolle der Gewebeproben bis zur Analyse der Gene und Proteine sowie der Erforschung ihrer Rolle bei der Entstehung der Tumoren", sagt Professor Rajalingam. Das Projekt sei ein gelungenes Beispiel dafür, wie man Fragestellungen und Ergebnisse von der Klinik ins Labor und zurück transferieren könne.

Originalpublikation: Proteogenomics analysis unveils a TFG-RET gene fusion and druggable targets in papillary thyroid carcinomas; Aswini Krishnan, Jean Berthelet, et al; Nature Communications 11, 2056 (2020); https://doi.org/10.1038/s41467-02015955-w

Kontakt:Univ.-Prof. Dr. Krishnaraj Rajalingam, Cell Biology Unit der Universitätsmedizin Mainz, E-Mail: krishna@uni-mainz.de

Quelle: PM 25.06.2020 der Universitätsmedizin der Johannes Gutenberg-Universität Mainz 